\section{Factors associated with low life life satisfaction in community-dwelling elderly: FIBRA Study}

\author{
Fatores associados à baixa satisfação com a \\ vida em idosos residentes na comunidade: \\ Estudo FIBRA
}




\section{Introduction}

Life satisfaction results from the individuals' overall cognitive assessment of their living conditions and achievements, comparing them to their needs and expectations and in light of their personal and sociocultural values 1 . Levels of satisfaction suffer the influence of adverse events that impact affective states, but these tend to return to baseline after the effects of the negative experiences have ceased. Old age is accompanied by increased likelihood of adverse events that affect well-being ${ }^{2}$.

There are no homogeneous data on the relations between gender and life satisfaction in old age, but the most common finding suggests that elderly women have lower levels of satisfaction than elderly men 2,3. Various explanations have been proposed, including the influence of the lifetime accumulation of educational, economic, and health disadvantages, whose effects are aggravated by physiological decline and other losses in old age. Being a man or woman itself has no impact on life satisfaction. What influences satisfaction are gender-related physical and social conditions. For elderly women, chronic illnesses, memory, self-rated health, social support, and social relations are the most relevant domains of life satisfaction. For elderly men, income and family relations are the domains with the greatest impact on levels of satisfaction 3,4 .

Age itself cannot be interpreted as a direct cause of decreased or increased life satisfaction. The relations between age and satisfaction are more consistently explained by the physical and social conditions in which the individual lives than by the time since birth. For young adults, satisfaction with work and income have a large influence on overall life satisfaction, while health is the domain that most contributes to levels of satisfaction in old age 5 . Levels of life satisfaction tend to decline with advancing age, when unfavorable living conditions emerge or are aggravated, such as chronic diseases, functional incapacity, restrictions to social contacts, reduce income, decreasing levels of activity and social involvement, and negative self-rated health 1,5.

The dynamic and complex interaction between good health conditions and functioning, adequacy of environmental conditions, and presence of personal resources results in greater social involvement, a favorable outcome associated with active or healthy aging 6 . High levels of social involvement result from good health conditions, preserved physical and cognitive capacities, motivation, adaptation to the environment, and opportunities 7. Involvement in social activities is associated with psychological and physi- cal benefits such as increased satisfaction, lower risk of depression, lower motor function decline, and lower risk of death 7. Relations with friends and family members contributes to the development of a feeling of belonging, allow contact with sources of satisfaction, and help the maintenance social support networks and functioning.

The advanced activities of daily living (AADL) are important indicators of social involvement in the elderly. They have greater physical and cognitive requirements than the instrumental (IADL) or the basic activities of daily living (BADL). While AADL allow the elderly to have direct contact while performing roles in the broader social environment and to be seen by others as active, productive, and involved participants 8, IADL place them in contact with activities of practical life performed in more restricted settings, including their own homes. Meanwhile, BADL are related to self-care and survival and become more automatic, routine, and circumscribed than other activities 7,8 .

The reduction in the ability to perform activities of daily living occurs by stages. Limitations begin with advanced or complex activities, and only affect the performance of IADL or BADL at a second or third stage ${ }^{8}$. When loss of muscle strength compromises mobility, it can lead to a decrease in involvement by the elderly in complex social, productive, and leisure-time activities 9 . Consequences may include the appearance or worsening of depressive symptoms, loneliness, dissatisfaction with life and inactivity, forming a vicious circle of adverse advents, with a negative impact on health, functioning, and well-being.

The Brazilian literature lacks studies on factors associated with low levels of satisfaction in the country's elderly people. Population-based studies on satisfaction in the elderly are important, but they have contemplated specific domains such as satisfaction with health services, transportation, and social relations 10,11. Other studies on life satisfaction used small samples of elderly treated at outpatient services 12,13. Knowledge on the relations between sociodemographic and health variables, functional performance, social involvement, and life satisfaction in Brazilian community-dwelling elderly contributes to the literature on the theme and helps to identify elements that are amenable to intervention in geriatric and gerontological care, especially in primary health care for the elderly.

The aim of this study was to identify factors associated with low life satisfaction in Brazilian community-dwelling elderly, including gender, age, chronic diseases, memory problems, urinary incontinence, falls, measures of functional performance (hand grip strength and walking 
speed), and social involvement, indicated by performance in AADL.

\section{Methods}

The study used information from the databank of the FIBRA Study, State University in Campinas (Unicamp) pole, which is part of the FIBRA network together with the University of São Paulo in Ribeirão Preto (USP-Ribeirão Preto), the Federal University in Minas Gerais (UFMG); and the State University of Rio de Janeiro (UERJ). FIBRA is the Portuguese-language acronym for "frailty in elderly Brazilians", referring to a research network consisting of these institutions and partner universities. The FIBRA Study, Unicamp pole, is a multicenter cross-sectional study involving probabilistic samples of elderly individuals 65 years or older, living in seven Brazilian cities selected by convenience. The objective is to investigate relations between frailty and health conditions, cognition, performance of activities of daily living, and psychosocial and sociodemographic variables.

\section{Sampling}

The FIBRA Study, Unicamp pole, included elderly from Belém (Pará State), Parnaíba (Piauí), Campina Grande (Paraíba), Poços de Caldas (Minas Gerais), the sub-district of Ermelino Matarazzo in São Paulo, Campinas (São Paulo), and Ivoti (Rio Grande do Sul). In each location, a simple random selection of urban census tracts was performed, and elderly men and women were recruited in gender and age quotas (65-69; 70 -74; 75-79; and $\geq 80$ years), which were proportional to their presence in the population of the selected census tracts 14 .

The study did not follow a perfect epidemiological design but involved multicenter data collection in cities located in three different geographic regions of Brazil, characterized by diverse socioeconomic and development conditions, as reflected by the respective Municipal Human Development Indices (IDH-M) and per capita Gross Domestic Product (GDP) 15. The samples of cities are not representative of the overall Brazilian population or that of the regions to which they belong. Based on this reasoning, no data corrections or weighting were performed. In all the cities, the study obtained a somewhat higher proportion of women than expected according to the design. The proportion of men was equivalent in all the cities except Poços de Caldas, which showed a slightly higher percentage of men than the other cities. The proportion of women proved equivalent in five cities and slightly higher than expected in Campina Grande and Ivoti 15.

For each location, we estimated the sample size needed for a $50 \%$ proportion of a given target characteristic (the value at which the resulting sample size is the maximum possible $-\mathrm{p}=0.50$; $\mathrm{q}=0.50$ - according to the cities' elderly populations). Significance was set at 5\% (alpha $=5 \%$; $Z=1.96)$. The sample error varied from $3 \%$ to $5 \%$. Based on these calculations, the sample size for the locations with more than a million inhabitants was set at 601 individuals, for an error of 4\% (Campinas and Belém). For the other cities with fewer than a million inhabitants, the sample value was set at 385 individuals, with an error of $5 \%$. The exception was the city of Ivoti, which had a total of 646 individuals 65 years or older. In this case, the sample calculation used was an estimated proportion of a finite population, with alpha set at $5 \%$, sample error of $5 \%$, and estimated $50 \%$ distribution of the target variable. With these parameters, the sample in Ivoti was estimated at 235 elderly.

\section{Recruitment}

Recruitment included two phases. The first involved radio, TV, and newspaper ads announcing the project. Religious and community leaders, coordinators of community centers for the elderly, and community health workers helped publicize the project, after being informed of the study's objectives and ethical precautions. Study coordinators from the local universities and the overall study coordinator gave awareness-raising talks to the elderly public in general and to the students and faculty at the participating universities in each location.

The second recruitment phase included visits to the households in each selected census tract by trained recruiters, who appeared in uniform and identified with photo badges, special T-shirts, knapsacks, leaflets, and interview materials identified with the logotypes of the FIBRA Study and the participating universities. The interviewers were undergraduate university students, community health workers, and church-related community outreach workers. The recruiters knocked or rang the doorbells and announced their presence at all the households in each selected census tract according to a predefined sequence marked on a map. At each household, they asked whether there was an elderly member that met the study's inclusion criteria. When there were two such members, both were interviewed and invited to participate. The recruitment in each census tract was complete when the quota was met for the estimated number of men and 
women and age groups for the tract, plus $50 \%$ to cover potential losses.

To meet the inclusion criteria, individuals needed to be 65 years or older, understand the instructions, agree to participate in the recruitment interview, and have their permanent residence in that census tract. Recruiters were instructed to use the following exclusion criteria: severe cognitive deficit suggestive of dementia, as evidenced by problems with memory, attention, orientation in time and space, and communication as reported by a family member or observed by the recruiters; use of wheelchair or being temporarily or permanently bedridden; severe sequelae from strokes, with localized loss of strength and/or aphasia; Parkinson disease in severe or unstable stage, compromising mobility, speech, or affect; serious hearing or sight impairments that heavily impeded communication; and terminal illness.

Elderly selected by the recruiters received leaflets on the objectives and nature of the study and a card with their name, address, date, time, and place for a data collection session at a club or community center, or a primary health clinic, school, or church. The card also included the names and telephones of the study coordinators in case the participants needed to contact them.

\section{Data collection}

Recruitment and data collection were done in successive waves. In each wave, enough elderly were recruited to meet the estimates in the sampling plan for one or more adjoining census tracts and were referred for data collection. Each wave was concluded when the expected number of elderly had undergone these procedures. Each elderly subject participated in a single session lasting 40 to 120 minutes, divided into two parts. In the first part, all the elderly $(n=3,478)$ in the seven locations were evaluated for the socio-demographic variables, blood pressure, anthropometric measurements, frailty, and cognitive functions. The score on the Mini-Mental State Examination (MMSE) minus one standard deviation 16 was used as the inclusion criterion for the second set of procedures in the second part of the data collection phase. This set included self-reported health conditions, independent performance of activities of daily living, expectation of care, depressive symptoms, perceived social support, and satisfaction. Elders that failed to achieve a sufficient score for inclusion in the second phase (25.4\% of the initial sample, ranging from $18.3 \%$ in Poços de Caldas to $38.2 \%$ in Parnaíba) were oriented on basic health care, received a leaflet on self-care, and were dismissed 15.

\section{Participants}

After the exclusions based on the MMSE, there were 2,592 elderly left. Among these, the currently study selected 2,472 participants aged 65 years or older, with no cognitive deficit suggestive of dementia and who had answered the target items for this study. This sample included 558 participants in Belém, 284 in Parnaíba, 229 in Campina Grande, 299 in Poços de Caldas, 291 in Ermelino Matarazzo, 655 in Campinas, and 156 in Ivoti.

\section{Variables and measurements}

- Sociodemographic: age and gender. Both were self-reported. Age was grouped into four brackets: 65-69; 70-74; 75-79; and $\geq 80$.

- Chronic diseases: the elderly were asked whether a doctor had diagnosed and informed them of the following diseases during the previous year: heart disease, high blood pressure, diabetes, stroke, tumor/cancer, arthritis, lung disease, depression, or osteoporosis, to which they answered "yes" or "no". Answers were categorized as follows: no disease, one or two, and three or more diseases.

- Signs and symptoms: the elderly were asked if they had experienced urinary incontinence, falls, or memory problems in the previous year. The elder answered "yes" or "no" to each of these conditions, which were analyzed separately.

- Functional performance: indicated by handgrip and gait speed. The handgrip measured in kilograms force (kg f) was obtained with a hydraulic dynamometer, Jamar model (Lafayette Instruments, Lafayette, USA), using the elder's dominant hand 17 . In the sitting position, participants performed three attempts with one minute resting interval. The gait speed test involved three consecutive measurements of the time (in seconds) which the individual took to walk 4.6 meters on a flat surface, on a straight line previously marked with colored adhesive tape. Gait speed was then calculated as meters per second 17 . Participants were allowed to use canes or walkers. Low handgrip was strength was defined by the lowest quintile in the sample for the average of the three attempts, adjusted for gender and body mass index $(\mathrm{BMI}=$ weight $/$ height 2$)$. Low gait speed was defined by the lowest quintile in the sample, adjusted for gender and height 17 . The cutoff scores for the both measurements were calculated specifically for each city.

- Social involvement: indicated by the performance of 13 AADL associated with sociability, leisure-time activity, productiveness, and social participation, as well as by independent performance of three IADL that require cogni- 
tive autonomy and independent interaction with the social environment. The former set includes the following activities: making visits, receiving visits, attending church, participating in social meetings, attending cultural events, driving, short trips, longer trips; volunteer work, paid work, participating on boards of directors and councils, attending university courses for the elderly, and participating in social groups in community 11,12. The second set included the following IADL: shopping, using transportation, and managing one's own finances. The AADL allowed the answers "never did", "stopping doing", or "still do" and the IADL included information on the need for help ("none", "partial", or "total”). For each participant, the score for the 16 activities consisted of the sum of the intact AADL, considering those that the individual had performed previously, and the completely independent IADL. Distribution of the scores was expressed in percentages and divided into three categories: $<61 \%$ - low social involvement; $61 \%$ to $85 \%$ moderate social involvement; and $>85 \%$ - high social involvement.

- Life satisfaction: measured by the following question: "Are you satisfied with your life?" The participant could answer: very satisfied, moderately satisfied, and not satisfied ${ }^{18}$. These answers were grouped into two categories: very satisfied = high satisfaction; moderately satisfied or not satisfied = low satisfaction. This is a routine and reliable way of evaluating individual satisfaction.

\section{Data analysis}

Statistical analyses used SPSS version 15.1 (SPSS Inc., Chicago, USA) and SAS version 8.02 (SAS Inst., Cary, USA). Application of the KolmogorovSmirnov test for normality showed that the distributions were not normal, so non-parametric tests were adopted (chi-square and Fisher exact test to compare the frequencies of nominal variables between the gender and age groups; Mann-Whitney and Kruskal-Wallis to test values for ordinal variables between the same groups). To study the relations between independent variables (gender, age, chronic diseases, signs and symptoms, handgrip, gait speed, and social participation) and the dependent variable (low life satisfaction), univariate and multivariate logistic regression analyses were performed, the latter with stepwise selection of variables, with a $95 \%$ confidence interval $(95 \% \mathrm{CI})$ for the resulting risk ratios. Statistical significance was set at $\mathrm{p} \geq 0.05$ for all the analyses.

\section{Ethical considerations}

The FIBRA Study, Unicamp pole, was approved by the Institutional Review Board of the School of Medicine at Unicamp under case review no. 208/2007. All participants signed an informed consent form before the data collection.

\section{Results}

In the total sample from the seven locations, $65.7 \%$ of participants were women $(n=1,625)$. Mean age was $72.2+5.5$ years. Only $11.3 \%$ of the elderly had no chronic disease, $49.7 \%$ had 1 or 2 , and $39 \%$ had 3 or more diseases. Urinary incontinence was reported by $26.3 \%$ of the elderly; $30.7 \%$ had suffered falls in the previous year, and $54.4 \%$ reported memory problems. The data on functional performance showed that $17 \%$ of the elderly scored low on handgrip and $16.9 \%$ on the gait speed. Half of the sample showed moderate social involvement scores, i.e., ranging from 61 to 85 percentage points, $24.2 \%$ had low social involvement (score $<61$ ) and $25.5 \%$ had high social involvement (> 85\%); $6.1 \%$ of the elderly reported that they were dissatisfied, $28.2 \%$ were moderately satisfied, and $65.6 \%$ were very satisfied with life (Table 1).

Table 1

Sample description according to health variables, functional performance, social involvement, and life satisfaction. FIBRA Study (Unicamp pole), São Paulo, Brazil, 2008-2009.

\begin{tabular}{|c|c|c|}
\hline Variables & $\mathbf{n}$ & $\%$ \\
\hline \multicolumn{3}{|c|}{ Number of chronic diseases } \\
\hline 0 & 279 & 11.30 \\
\hline $1-2$ & 1,226 & 49.64 \\
\hline$\geq 3$ & 965 & 39.07 \\
\hline \multicolumn{3}{|l|}{ Signs and symptoms } \\
\hline Urinary incontinence & 650 & 26.32 \\
\hline Falls & 742 & 30.71 \\
\hline Memory problems & 1,330 & 54.42 \\
\hline \multicolumn{3}{|l|}{ Functional performance } \\
\hline Low handgrip & 417 & 17.01 \\
\hline Low gait speed & 415 & 16.91 \\
\hline \multicolumn{3}{|l|}{ Social involvement } \\
\hline$<61$ & 598 & 24.22 \\
\hline $61-85$ & 1,240 & 50.22 \\
\hline$>85$ & 631 & 25.56 \\
\hline \multicolumn{3}{|l|}{ Life satisfaction } \\
\hline Low & 151 & 6.11 \\
\hline Intermediate & 698 & 28.24 \\
\hline Low & 1,623 & 65.66 \\
\hline
\end{tabular}


The mean number of chronic diseases was significantly higher in women (2.4) than in men (1.7). Gait speed was significantly lower in women $(0.87 \mathrm{~m} / \mathrm{s})$ than in men $(0.98 \mathrm{~m} / \mathrm{s})$, and women's handgrip $(20.6 \mathrm{~kg}$ f) was significantly lower than men's (33.8kg f). However, women's social involvement score was higher (73\%) than men's (71.3\%). The elderly aged 80 years and older had significantly lower mean gait speed $(0.81 \mathrm{~m} / \mathrm{s})$ and lower handgrip (22.1 kg f) and social involvement $(64.6 \%)$ than in the younger groups. In all these comparisons the p-value was $<0.001$. No statistically significant differences were observed in mean levels of satisfaction between men and women or between the four age groups. More women $(58.5 \%)$ than men $(46.8 \%)$ reported memory problems. More women $(28.9 \%)$ than men $(22.1 \%)$ reported urinary incontinence. The $\mathrm{p}$-values for these chi-square tests were $<0.001$. No statistically significant differences were observed between the genders for falls or between the age groups for memory problems, urinary incontinence, or falls (Table 2).

Most of the elderly reported that they still received visits (91.8\%), attended church $(89.1 \%)$, and made visits $(77.4 \%)$. The AADL in which the elderly reported never participating were attending to University of the Third Age (UNATI) $(87.8 \%$ were non-participation), making part of Boards of Directors or Councils (70.3\%), driving (66.9\%), attending community centers for the elderly (61.7\%), and volunteer work (60.2\%). The activities most frequently interrupted by the elders were paid work $(61.2 \%)$, participation in cultural events $(36.2 \%)$, and making long trips (30.6\%) (Table 3).

Given the limited heterogeneity in the gender and age groups in the seven cities after applying the MMSE, the samples were considered jointly in the univariate regression analysis, a procedure previously adopted in other analyses. The multivariate regression analysis was adjusted for the cities to avoid confounding.

The univariate logistic regression showed independent associations between sociodemographic and health-related variables, functional performance, and social involvement and low life satisfaction. Variables that were statistically associated with lower life satisfaction included: three or more self-reported chronic diseases $(\mathrm{OR}=2.14)$, self-reported memory problems $(\mathrm{OR}=1.76)$, low social involvement $(\mathrm{OR}=1.73)$, self-reported urinary incontinence $(\mathrm{OR}=1.54)$, low handgrip $(\mathrm{OR}=1.46)$, falls in the previous year $(\mathrm{OR}=1.34)$, low gait speed $(\mathrm{OR}=1.29)$, and moderate social involvement $(\mathrm{OR}=1.28)$.

According to the multivariate logistic regression with stepwise selection of variables, factors that were simultaneously associated with low life satisfaction were: three or more diseases $(\mathrm{OR}=2.04)$, memory problems $(\mathrm{OR}=1.59)$, low social involvement $(\mathrm{OR}=1.47)$, low handgrip $(\mathrm{OR}=1.29)$, and self-reported urinary incontinence $(\mathrm{OR}=1.27)$ (Table 5).

\section{Discussion}

Low life satisfaction was associated with more chronic diseases, replicating data from other studies 5. Good health is a relevant issue in old age, since it allows maintaining behavioral competencies, activity, productiveness, social participation, and self-care, which are related to life satisfaction 5,9. Studies have shown that health problems tend to jeopardize quality of life and well-being when they affect functional capacity ${ }^{18}$.

Chronic diseases, functional performance, social involvement, and life satisfaction according to gender and age. FIBRA Study (Unicamp pole), São Paulo, Brazil, 2008-2009

\begin{tabular}{|c|c|c|c|c|c|c|c|c|c|c|c|c|c|c|}
\hline & \multicolumn{5}{|c|}{ Gender } & \multicolumn{9}{|c|}{ Age (years) } \\
\hline & \multicolumn{2}{|c|}{ Male } & \multicolumn{2}{|c|}{ Female } & \multirow[t]{2}{*}{$\mathrm{p}$-value * } & \multicolumn{2}{|c|}{$65-69$} & \multicolumn{2}{|c|}{$70-74$} & \multicolumn{2}{|c|}{$75-79$} & \multicolumn{2}{|c|}{$\geq 80$} & \multirow[t]{2}{*}{$\mathrm{p}$-value ** } \\
\hline & $\mathrm{n}$ & Mean & $\mathrm{n}$ & Mean & & $\mathrm{n}$ & Mean & $\mathrm{n}$ & Mean & $\mathrm{n}$ & Mean & $\mathrm{n}$ & Mean & \\
\hline Chronic diseases & 846 & 1.76 & 1624 & 2.4 & $<0.001$ & 939 & 2.19 & 773 & 2.2 & 467 & 2.3 & 291 & 2.1 & 0.084 \\
\hline Handgrip (kg f) & 839 & 33.7 & 1617 & 20.6 & $<0.001$ & 932 & 26.3 & 767 & 26.1 & 465 & 23 & 289 & 22.1 & $<0.001$ \\
\hline Gait speed (m/s) & 838 & 0.98 & 1616 & 0.87 & $<0.001$ & 935 & 0.95 & 765 & 0.92 & 465 & 0.88 & 289 & 0.81 & $<0.001$ \\
\hline Social involvement & 846 & 71.3 & 1623 & 73 & $<0.001$ & 939 & 75.7 & 773 & 72.4 & 466 & 70.9 & 291 & 64.6 & $<0.001$ \\
\hline Life satisfaction & 847 & 2.4 & 1625 & 2.4 & 0.256 & 941 & 2.4 & 773 & 2.4 & 467 & 2.4 & 291 & 2.4 & 0.145 \\
\hline
\end{tabular}

* Mann-Whitney U test;

**Kruskal-Wallis test. 
Social involvement of the elderly measured by advanced activities of daily living (AADL). FIBRA Study (Unicamp pole), São Paulo, Brazil, 2008-2009.

\begin{tabular}{|c|c|c|c|c|c|c|}
\hline & \multicolumn{2}{|c|}{ Still do } & \multicolumn{2}{|c|}{ Stopped doing } & \multicolumn{2}{|c|}{ Never did } \\
\hline & $\mathbf{n}$ & $\%$ & $\mathbf{n}$ & $\%$ & $\mathbf{N}$ & $\%$ \\
\hline Receive visits & 2,266 & 91.85 & 139 & 5.63 & 62 & 2.51 \\
\hline Attend church & 2,202 & 89.19 & 221 & 8.95 & 46 & 1.86 \\
\hline Make visits & 1,913 & 77.48 & 384 & 15.55 & 172 & 6.97 \\
\hline Short trips & 1,733 & 70.30 & 585 & 23.73 & 147 & 5.96 \\
\hline Long trips & 1,405 & 56.91 & 756 & 30.62 & 308 & 12.47 \\
\hline Attend parties & 1,214 & 49.21 & 675 & 27.36 & 578 & 23.43 \\
\hline Community centers for elderly & 639 & 25.94 & 304 & 12.34 & 1,520 & 61.71 \\
\hline Cultural events & 635 & 25.71 & 896 & 36.28 & 939 & 38.02 \\
\hline Volunteer work & 555 & 22.59 & 423 & 17.22 & 1,479 & 60.20 \\
\hline Drive car & 457 & 18.53 & 357 & 14.48 & 1,652 & 66.99 \\
\hline Paid work & 412 & 16.75 & 1,507 & 61.26 & 541 & 21.99 \\
\hline Boards of directors and councils & 266 & 10.81 & 465 & 18.89 & 1,730 & 70.30 \\
\hline University of the Third Age (UNATI) & 43 & 4.55 & 72 & 7.62 & 830 & 87.83 \\
\hline
\end{tabular}

Subjective memory problems are associated with low performance on cognitive function tests in the elderly. Difficulty with memory is associated with functional incapacity and may indicate risk of developing dementia. It is heavily influenced by the sense of personal efficacy, schooling, and socioeconomic status 20 . Good cognitive status is considered one of the prerequisites for performing advanced activities of daily living, which require the capacity to make decisions and communicate, as well as high-level mental and social skills 8,21 . When such skills are compromised, older individuals reduce their community participation and involvement in social activities, which can affect their life satisfaction. Social activities also provide intellectual stimuli through social interaction 22 .

Elderly individuals that report concurrent chronic diseases often have diabetes, high blood pressure, and cardiovascular diseases, the most prevalent disease conditions in this population 19. Such diseases are known to affect the systemic circulation and can jeopardize the supply of oxygen and other nutrients to the brain 20 . They can thus cause memory problems and other frequent cognitive dysfunctions in old age 21,22 . The elderly with difficulty to maintaining attention and remembering events feel frustrated when they meet others or face complex activities, a reason for reducing their social involvement 8,21 .

Elderly with moderate to low social participation scores show increased risk of reporting dissatisfaction with life. Social participation is the positive and desirable outcome recommended by active aging policy and the International Classification of Functioning, Disability, and Health 6 . It results from the control of diseases and dysfunctions, maintenance of functional capacity, and adaptation to the social and environmental context, which in turn derives from demographic and socioeconomic variables such as marital status, age, gender, schooling, occupation, and family arrangements 7,9.

More elderly tend to maintain their participation in less-demanding activities in the physical, cognitive, and social domains, such as making and receiving visits and attending church. Fewer participants performed social activities involving more complex demands, such as paid work, participating in parties and cultural events, and making long trips. Common reasons for interrupting such activities are their dependence on mobility, physical conditioning, and cognitive functions 9,21. AADL indicate the elder's level of social involvement, and interruption of these activities is an early indicator of functional losses that tend to worsen over time.

The emergence and worsening of diseases and physical difficulties can cause loss of interest and withdrawal from activities with considerable physical and mental demands. Meanwhile, activities such as participating in parties and cultural events, traveling, attending university courses for the elderly (UNATI), performing volunteer work, and participating in community associations depend to a major extent on the 
Independent associations between low life satisfaction, demographic and health indicators, functional performance, and social involvement. FIBRA Study, Unicamp pole, São Paulo, Brazil, 2008-2009.

\begin{tabular}{|c|c|c|c|}
\hline Variable/Categories & $\mathrm{p}$-value & OR & $95 \% \mathrm{Cl}$ \\
\hline \multicolumn{4}{|l|}{ Age (years) } \\
\hline 65-69 (reference) & - & 1.00 & - \\
\hline $70-74$ & 0.684 & 0.96 & $0.79-1.17$ \\
\hline $75-79$ & 0.510 & 0.92 & $0.73-1.17$ \\
\hline$\geq 80$ & 0.978 & 1.00 & $0.76-1.32$ \\
\hline \multicolumn{4}{|l|}{ Gender } \\
\hline Male (reference) & - & 1.00 & - \\
\hline Female & 0.599 & 1.05 & $0.88-1.25$ \\
\hline \multicolumn{4}{|l|}{ Low hand grip strength } \\
\hline No (reference) & - & 1.00 & - \\
\hline Yes & $<0.001$ & 1.46 & $1.18-1.81$ \\
\hline \multicolumn{4}{|l|}{ Low walking speed } \\
\hline No (reference) & - & 1.00 & - \\
\hline Yes & 0.022 & 1.29 & $1.04-1.60$ \\
\hline \multicolumn{4}{|l|}{ Number of diseases } \\
\hline 0 (reference) & - & 1.00 & - \\
\hline $1-2$ & 0.118 & 1.27 & $0.94-1.70$ \\
\hline 3 or more & $<0.001$ & 2.14 & $1.59-2.88$ \\
\hline \multicolumn{4}{|l|}{ Urinary incontinence } \\
\hline No (reference) & - & 1.00 & - \\
\hline Yes & $<0.001$ & 1.54 & $1.28-1.85$ \\
\hline \multicolumn{4}{|l|}{ Memory problems } \\
\hline No (reference) & - & 1.00 & - \\
\hline Yes & $<0.001$ & 1.76 & $1.48-2.08$ \\
\hline \multicolumn{4}{|l|}{ Falls } \\
\hline No (reference) & - & 1.00 & - \\
\hline Yes & 0.001 & 1.34 & $1.12-1.61$ \\
\hline \multicolumn{4}{|l|}{ Social involvement } \\
\hline$>85 \%$ (reference) & - & 1.00 & - \\
\hline $61 \%-85 \%$ & 0.021 & 1.28 & $1.04-1.58$ \\
\hline$<61 \%$ & $<0.001$ & 1.73 & $1.36-2.19$ \\
\hline
\end{tabular}

95\% Cl: 95\% confidence interval; OR: odds ratio for decreased life satisfaction.

Note: $N=2,472$ (1,623 very satisfied and 849 not satisfied or moderately satisfied).

elder's lifetime social and economic opportunities, lifestyle, motivations, and personality factors. In addition, withdrawal from social activities can reflect the use of selection and compensation strategies in the face of difficulties that emerge in old age 23,24 . Although being socially involved is more favorable for maintaining satisfaction than being socially withdrawn or isolated, the decision to withdraw to spare strength, avoid errors and accidents, and invest selectively in domains with preserved competencies (aimed at optimizing individual functioning) can prove highly adaptive for the elderly.
In this study, low performance on the strength and speed tests was associated with low life satisfaction. Low handgrip and low gait speed indicate loss of overall muscle strength, which can be related to difficulties in the physical mobility domain, affecting participation in social activities and thus contributing to the decreasing of life satisfaction 9 . On the other hand, losses of muscle strength often involve positive physical and emotional adaptation, expressed as the selection of activities that the elder considers most relevant, and an intentional cutback in the intensity of performance and time spent on a given ac- 
Multiple relations between decreased life satisfaction, health, functional performance, and social involvement, adjusted by city. FIBRA Study (Unicamp pole), São Paulo, Brazil, 2008-2009.

\begin{tabular}{|c|c|c|c|}
\hline Variables/Categories & p-value & OR & $95 \% \mathrm{Cl}$ \\
\hline \multicolumn{4}{|l|}{ Number of diseases } \\
\hline 0 (reference) & - & 1.00 & - \\
\hline $1-2$ & 0.075 & 1.34 & $0.98-1.83$ \\
\hline 3 or more & $<0.001$ & 2.07 & $1.51-2.84$ \\
\hline \multicolumn{4}{|l|}{ Memory problems } \\
\hline No (reference) & - & 1.00 & - \\
\hline Yes & $<0.001$ & 1.60 & 1.33-1.92 \\
\hline \multicolumn{4}{|l|}{ Social involvement } \\
\hline$>85 \%$ (reference) & - & 1.00 & - \\
\hline $61 \%-85 \%$ & 0.091 & 1.21 & $0.97-1.50$ \\
\hline$<61 \%$ & 0.005 & 1.43 & $1.12-1.84$ \\
\hline \multicolumn{4}{|l|}{ Low hand grip strength } \\
\hline No (reference) & - & 1.00 & - \\
\hline Yes & 0.030 & 1.29 & $1.02-1.62$ \\
\hline \multicolumn{4}{|l|}{ Urinary incontinence } \\
\hline No (reference) & - & 1.00 & - \\
\hline Yes & 0.015 & 1.28 & $1.05-1.57$ \\
\hline
\end{tabular}

95\% Cl: 95\% confidence interval; OR: odds ratio for decreased satisfaction.

Note: $N=2,360$ (1,548 very satisfied and 812 not satisfied or moderately satisfied). Reference: reference level; multivariate

logistic regression analysis with stepwise selection of variables.

tivity 24 . Urinary incontinence is another adverse health condition that requires adaptive strategies potentially resulting in a reduction in social contact and participation in activities away from home. Elders with urinary incontinence thus tend to avoid risks and embarrassments, but end up exposed to the harmful effects of sedentary lifestyle and social isolation, which are associated with dissatisfaction 25 .

Falls have a major impact on quality of life and well-being in the elderly and are seen as indicative of harm related not only to physical health and functioning, but also to affective issues 26. Psychosocial issues related to falls include fear of falling and a low feeling of efficacy in avoiding falls, which in turn are related to sedentary lifestyle and social isolation 26. Dias et al. 27 observed that elderly who reported restrictions in activities for fear of falling presented more depressive symptoms and exhaustion, lower selfefficacy in relation to falls, lower gait speed, less participation in social activities, less autonomy in performing instrumental activities of daily living, more diseases, and worse self-rated health. In the current study, falls in the previous year were associated with low life satisfaction.
Data on gender relations, age, and life satisfaction do not express linear relations between the first two and the latter 28 . For men, satisfaction is mediated by conjugal status, such that widowers have lower levels of life satisfaction than widows, probably because they are more affected by the lack of social support previously provided by the female partner. For women, high levels of life satisfaction depend on good health conditions, sufficient social support to supply their needs, and involvement in an effective network of informal social relations 3,28.

The absence of an association between life satisfaction and age is acknowledged as a paradoxical event. If income, social support, level of activity, and physical and mental health tend to decline with age, levels of satisfaction would be expected to reduced among the oldest, but this does not necessarily happen. The capacity for emotional regulation is known to be a skill that increases with years, thanks to which many elderly are satisfied with life, even in adverse situations. Elderly with greater capacity to adjust their goals and expectations to the available resources display greater resilience in the face of frustrations, which translates as higher levels of 
satisfaction 23,24. Coping strategies are adopted by the elderly to overcome losses and difficulties and achieve the adaptation needed for good functioning. In addition, maintaining social contacts and productive activities plays a protective role against low satisfaction in old age 23,24. The selection, optimization, and compensation model 24 provides for selective changes in motivational preferences, in efforts to compensate and adapt physical and cognitive capacities, and to optimize of emotional behaviors in old age. According to the socioemotional selectivity theory 23 , the elderly value positive socioemotional experiences more than negative ones and prefer social relations that bring emotional comfort as compared to information and status.

The current study's design led to the exclusion of elderly with mobility problems and low cognitive status, because in order to participate in the study they had to get from their homes to the data collection site, located in the neighborhood. The data thus showed small variability, which however did not jeopardize their validity, since it was still possible to identify the factors as- sociated with low satisfaction in the elderly. Such factors proved prevalent in this population, even though the sample mainly included more active, independent, and motivated elders. Longitudinal studies could help shed light on the causal relationships between the variables analyzed in this study and thereby provide relevant information for health policies in old age.

\section{Conclusion}

Low life satisfaction was associated with the presence of three or more chronic diseases, memory problems, low social involvement, low grip strength, and self-reported urinary incontinence. These factors thus become targets for gerontological and interdisciplinary action with the aim of increasing life satisfaction in the elderly. Management of health conditions and functioning together with policies to encourage social participation, should thus be priorities in the approach to the elderly at all levels of care.

\section{Resumen}

Los objetivos fueron identificar los factores asociados a la baja satisfacción en adultos mayores y describirlas en función del sexo y la edad. Se entrevistó a 2.472 personas de 65 años o más, sin deterioro cognitivo sugestivo de demencia, de muestras aleatorias de siete ciudades en Brasil. Las medidas fueron auto-reporte, excepto el desempeño funcional indica en las pruebas de fuerza de agarre y velocidad de la marcha. Las mujeres tenían más enfermedades, rendimiento funcional peor y mayor participación social, en comparación con los hombres. Los participantes de más edad mostraron peor desempeño funcional y menos participación social que los más jóvenes. Se asociaron con una baja satisfacción: tres o más enfermedades, problemas de memoria, el bajo nivel de participación social, baja fuerza de prensión y la incontinencia urinaria. La salud, el rendimiento funcional y la interación social interactúan con el bienestar, por lo que la intervención en estos aspectos favorecen la calidad de vida de los ancianos.

Salud del Anciano; Envejecimiento; Fuerza Muscular; Calidad de Vida 


\section{Contributors}

J. M. Pinto and A. L. Neri participated in the data analysis and interpretation and writing of the article.

\section{Acknowledgments}

The authors wish to thank Monica Sanches Yassuda, José Guilherme de Arruda Moura, Ludgleydson F. de Araújo, Maria do Carmo Eulálio, Benedita Edina Cabral, Maria Eliane Catunda de Siqueira, Efigênia Passarelli Mantovani, Andrea Cristina Garofe Fortes-Burgos, Flavia Silva Arbex Borim, Stella Vital de Souza Torres, and Débora Dias da Silva Harmitt. The research funding agencies $\mathrm{CNPq}$ and Capes provided financial support for the study.

\section{References}

1. Diener E, Ryan K. Subjective well-being: a general overview. South African J Psychol 2009; 39: 391-406.

2. George LK. Still happy after all these years: research frontiers on subjective well-being in later life. J Gerontol Psychol Sci Soc Sci 2010; 65B:331-9.

3. Oshio T. Gender differences in the associations of life satisfaction with family and social relations among the Japanese elderly. Cross Cult Gerontol 2010; 27:259-74.

4. Castillo-Carniglia A, Albala C, Gangour AD, Uauy. Factores asociados a satisfacción vital en una cohort de adultos mayores de Santiago, Chile. Gac Sanit 2012; 26:414-20.

5. Enkvist A, Ekstrom H, Elmstahl S. Life satisfaction (LS) and symptoms among the oldest-old: results from the longitudinal population study called good aging in Skane (GAS). Arch Gerontol Geriatr 2012; 54:146-50.

6. Organização Pan-Americana da Saúde, Organização Mundial da Saúde. Classificação internacional de funcionalidade, incapacidade e saúde (CIF). São Paulo: Edusp; 2011.

7. Dias EG, Duarte YAO, Almeida HM, Lebrão ML. Caracterização das atividades avançadas de vida diária (AAVDS): um estudo de revisão. Rev Ter Ocup 2011; 22:45-51.
8. Reuben DB, Laliberte L, Hiris J, Mor V. A hierarchical exercise scale to measure function at the advanced activities of daily living (AADL) level. J Am Geriatr Soc 1990; 38:855-61.

9. Lee CT, Yeh CJ, Lee MC, Lin HS, Chen VCH, Hsieh $\mathrm{MH}$, et al. Leisure activity, mobility limitation and stress as modifiable risk factors for depressive symptoms in the elderly: results of a national longitudinal study. Arch Gerontol Geriatr 2012; 54:221-9.

10. Luz TCB, César CC, Lima-Costa MF, Proietti FA. Satisfaction with the neighborhood environment and health in older elderly: cross-sectional evidence from the Bambuí cohort study of aging. Cad Saúde Pública 2011; 27 Suppl 3:S390-8.

11. Lima-Costa MF, Loyola Filho AI. Fatores associados ao uso e a satisfação com os serviços de saúde entre usuários do Sistema Único de Saúde na Região Metropolitana de Belo Horizonte, Estado de Minas Gerais, Brasil. Epidemiol Serv Saúde 2008; 7:247-57.

12. Sposito G, Diogo MJD, Cintra FA, Neri AL, Guariento ME. Relações entre bem estar subjetivo, mobilidade e independência funcional por função de grupos de faixas etárias e de gêneros em idosos. Acta Fisiátrica 2010; 17:103-8. 
13. Diogo MJD. Satisfação global com a vida e determinados domínios entre idosos com amputação de membros inferiores. Rev Panam Salud Pública 2003; 13:395-9.

14. Instituto Brasileiro de Geografia e Estatística. Bases de informação por distrito censitário [DVD]. Rio de Janeiro: Instituto Brasileiro de Geografia e Estatísticas; 2002.

15. Neri AL, Yassuda MS, Araújo LF, Eulálio MC, Cabral BE, Siqueira MEC, et al. Metodologia e perfil sociodemográfico, cognitivo e de fragilidade de idosos comunitários de sete cidades brasileiras: Estudo FIBRA. Cad Saúde Pública 2013; 29:778-92.

16. Brucki SMD, Nitrini R, Caramelli P, Bertolucci PHF, Okamoto IH. Sugestões para o uso do Mini-Exame do Estado Mental no Brasil. Arq Neuropsiquiatr 2003; 61:777-81.

17. Fried LP, Tangen CM, Walston J, Newman AB, Hirsch C, Gottdiener J, et al. Frailty in older adults: evidence for a phenotype. J Gerontol A Biol Sci Med Sci 2001; 56:M146-56.

18. Neri AL. Bienestar subjetivo en la vida adulta y en la vejez: hacia una psicologia positiva en America Latina. Rev Latinoam Psicol 2002; 34:55-74.

19. Marengoni A, Angleman S, Melis R, Mangialasche F, Karp A, Garmen A, et al. Aging with multimorbidity: a systematic review of the literature. Ageing Res Rev 2011; 10:430-9.

20. Leon JB, Mitchell AJ, Vega S, Bermejo-Pareja F. A population-based study of cognitive function in older people with subjective memory complaints. J Alzheimers Dis 2010; 22:159-70.

21. Iwasa H, Yoshida Y, Kai I, Suzuki T, Kim H, Yoshida H. Leisure activities and cognitive function in elderly community-dwelling individuals in Japan: a 5-year prospective cohort study. J Psychosomatic Res 2012; 72:159-64.
22. Wang H, Karp A, Winblad B, Fratiglioni L. Late-life engagement in social and leisure activities is associated with a decreased risk of dementia: a longitudinal study from the Kungsholmen. Am J Epidemiol 2002; 155:1081-7.

23. Scheibe S, Carstensen LL. Emotional aging: recent findings and future trends. J Gerontol Psych Sci 2010; 65B:135-44.

24. Baltes PB, Baltes MM. Psychological perspectives on successful aging: the model of selective optimization with compensation. In: Baltes PB, Baltes MM, editors. Successful aging: perspectives from the behavioral sciences. Cambridge: Cambridge University Press; 1990. p. 1-34.

25. Tamanini JTN, Lebrão ML, Duarte YAO, Santos JLF, Laurenti R. Analysis of the prevalence of and factors associated with urinary incontinence among elderly people in the Municipality of São Paulo, Brazil: SABE Study (Health, Well-being and Aging). Cad Saúde Pública 2009; 25:1756-62.

26. Perracini MR, Ramos LR. Fatores associados a quedas em uma corte de idosos residentes na comunidade. Rev Saúde Pública 2002; 36:709-16.

27. Dias RC, Freire MTF, Santos EGS, Vieira RA, Dias JMD, Perracini MR. Características associadas às restrições de atividades por medo de cair em idosos comunitários. Rev Bras Fisioter 2011; 15: 406-13.

28. Pinquart M, Sorensen S. Gender differences in self-concept and psychological well-being in old age: a meta-analysis. J Gerontol B Psychol Sci Soc Sci 2001; 56:P195-213.

Submitted on 03/Dec/2012

Final version resubmitted on 22/May/2013

Approved on 02/Jul/2013 